\title{
Study of Nanfeng Nuo Dance in Jiangxi Province Under the Influence of Farming Culture
}

\author{
Limin Chen ${ }^{1, *}$
}

\author{
${ }^{1}$ Jiujiang University, Jiujiang, Jiangxi, China \\ *Corresponding author. Email: 153523142@qq.com
}

\begin{abstract}
Nanfeng Nuo dance in Jiangxi Province is a historical relic of traditional culture, which embodies the living customs, national characteristics and cultural connotation accumulated through long-term farming. And it is the wisdom crystallization left to Chinese descendants by farming civilization for thousands of years. The development of farming economy and social progress directly affect the development of Nanfeng Nuo dance. Therefore, against the background of farming culture, the study of Nanfeng Nuo dance has theoretical reference value and practical significance. This paper first makes a brief analysis of the historical and cultural origins of Nanfeng Nuo dance to show its cultural roots. And then, it introduces several representative Nuo dances one by one, so that people can have a general understanding of Nanfeng Nuo dance. Finally, it focuses on the analysis of the farming cultural characteristics of Nanfeng Nuo dance. In order to study the cultural characteristics of Nanfeng Nuo dance, the relationship between the sacrificial custom, religious belief and reproduction worship and farming culture is summarized.
\end{abstract}

Keywords: farming culture, Nanfeng Nuo dance, characteristic analysis

\section{INTRODUCTION}

China is an ancient country with thousands of years of civilization history. The developed traditional agriculture constitutes the basic color of Chinese civilization history. Farming culture is a kind of cultural form related to agriculture created by farmers in the process of long-term agricultural production and life practice in a certain region. It is a part of agricultural culture, which is manifested in the material and spiritual aspects ${ }^{1}$. Nuo is an ancient ritual of exorcism in the process of early social development, and dance is an important part of it. Nuo dance is the farmer's dance and the product of farming culture, which has a deep brand in the development of Nuo dance. Jiangxi Nuo dance is an important form of Chinese folk dance, a "living fossil" in the history of dance, and one of the important intangible cultural heritages of mankind. In recent ten years, with the "exorcism research craze" in China and foreign countries, Jiangxi Nuo dance has attracted more and more attention from dance researchers all over the world, especially in East Asia.

Nanfeng County of Jiangxi Province is located in the east of Jiangxi Province and adjacent to Fujian Province in the East. It is a county-level administrative

Sun Dandan. Research on Landscape Design of Agricultural Expo Park Based on Farming Culture [D]. Xi'an University of Architecture and Technology, 2017: 9. district under the jurisdiction of Fuzhou City. It is located between $116^{\circ} 09^{\prime}-116^{\circ} 45^{\prime}$ East longitude and $26^{\circ} 26^{\circ} 51^{\prime}-27^{\circ} 21^{\prime}$ Northern latitude. The traffic in the county is developed, which is the main road from east Jiangxi to southern Jiangxi. The topography of Nanfeng County is characterized by "low in the middle, separated from southeast and northwest", and Xujiang River (Fuhe River) passes through the county. Except for the plain areas along the river, most are hilly areas. The complex geographical environment preserves the ancient and simple Nuo culture.

Nanfeng Nuo dance is a typical representative of Jiangxi Nuo dance. It has rich data, rich cultural accumulation, complete Nuo dance ceremony, simple dance form and rich original style, which have important research value. This paper takes Nanfeng Nuo dance in Jiangxi Province of China as the research object. Through literature induction and field investigation, this paper analyzes the influence of farming culture on Nanfeng Nuo dance from the aspects of folk custom, religion, drama and reproductive worship, so as to investigate the cultural and artistic value of Nanfeng Nuo dance.

\section{THE HISTORICAL ORIGIN OF NANFENG NuO dance in Jiangxi Province}

Nanfeng Nuo dance is a kind of dance performed in front of the stage, ancestral hall, memorial tablet or Nuo 
God wearing wooden mask during the Spring Festival, as well as Nuo dance, Zhuma dance, hehe dance and eight immortals dance. ${ }^{2}$ Nanfeng Nuo dance has experienced brilliant and declining history, but it has never been broken. It has a history of more than 2000 years since the Han Dynasty, because of the record of Nuo handed down Nanfeng in "Jinshayushi Nuoshenbianji". In "the collection of Chinese folk dance - Jiangxi volume" and "Chinese dance · Jiangxi volume", there is also a saying that Nanfeng Ganfang Nuo began in the Tang Dynasty. The poem "Guannuo" written by Liu Tang, a hermit in Nanfeng of the Southern Song Dynasty, also had a detailed record of the early Nuo opera. Nanfeng Nuo dance experienced a short period of depression in Yuan Dynasty, and then became prosperous again in Ming and Qing Dynasties (Nuo dance of Shanggan village and Shiyou village in Nanfeng County began in Ming Dynasty). After the founding of the people's Republic of China, the fate of Nuo dance in Nanfeng has been fluctuating with the influence of social thoughts such as "feudal superstition" and "exorcism upsurge", but it has finally moved from a low ebb to another climax. In 1992, Nanfeng County was named "the land of Nuo dance" by the Department of Culture of Jiangxi Province. In 1996 and 2008, the Ministry of Culture named Nanfeng as "the hometown of Chinese folk art (Nuo dance art)". Nanfeng Nuo dance was listed in the first batch of national intangible cultural heritage projects in 2006. The continuous strengthening of protection consciousness of contemporary intangible cultural heritage has created new conditions for the further development of Nanfeng Nuo dance. In recent years, Nanfeng Nuo dance has been performed in China and foreign countries for many times (as shown in "Fig. 1"), which has caused great repercussions in China and foreign countries.

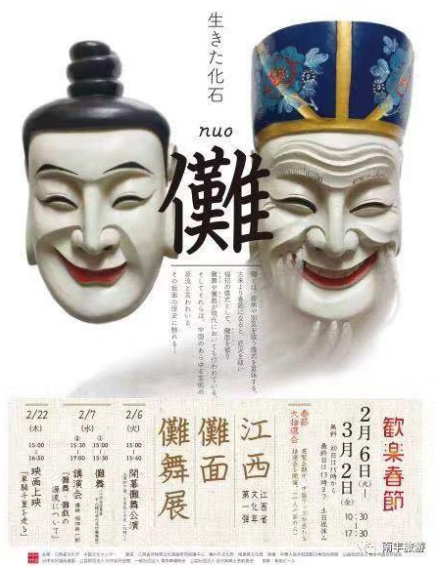

Fig. 1. Leaflet of Nanfeng Nuo dance performance in Tokyo, Japan.

Nanfeng County Annals Compilation Committee. Nanfeng County Annals [M]. Tsinghua Tongfang Electronic CD Press, 2006. 12: 359

\section{INTRODUCTION OF NANFENG NUO DANCE CATEgories IN Jiangxi Province}

Nanfeng Nuo dance has rich categories and various forms, among which Shiyou Nuo dance, Shanggan Nuo dance, Gengxi Zhuma dance and Shuibei hehe are the most typical and important representatives.

\section{A. Shiyou Nuo dance}

Shiyou village is located in the north of Sanxi Township, Nanfeng County, Jiangxi Province. Township Nuo in Shiyou village is one of the oldest Nuo troupes in Nanfeng County. It not only continues the ancient Nuo exorcism ceremony, but also remains a lot of Nuo cultural information, which is one of the typical materials to study Chinese Nuo culture. The village is dominated by the $\mathrm{Wu}$ family, and still maintains the hereditary system of the headman, who has the dignity of the family and is in charge of the main affairs of Nuo troupe. There is a famous Nuo temple in the village. The half-month Nuo performance starts from here. Shiyou Nuo dance (shown in "Fig. 2") has a strong flavor of life. The dancing is simple and mysterious, crude and grotesque. The performance is meticulous and the ritual is relatively complete. From the lunar new year to the 20th day of the first month, its structure and program can be divided into six parts: stepping on the stage, having the exorcise, performing Nuo, searching Nuo, yuan Nuo and the sitting. Among them, "performing Nuo" is mainly dance performance. At present, there are eight programs, "Kaishan", "Zhiqian", "Leigong", "Zhongkui Zuijiu", "Tiaodeng", "Shuangbolang", "Nuo Gong and Nuo Po", and "Ji Dao". They are accompanied by a drum and a gong. They are intended to hope that the new year will be a good one, with no disasters, a bumper harvest and a peaceful world. Nuo performance has lasted for more than 600 years in Shiyou village.

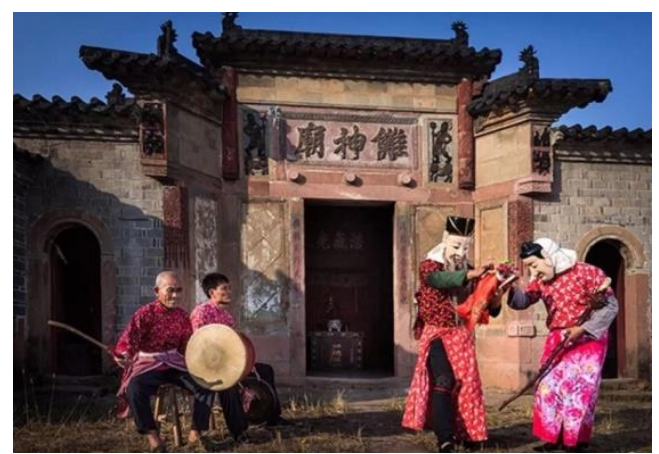

Fig. 2. Shiyou Nuo dance.

\section{B. Shanggan Nuo dance}

From the first day of the first month to the 19th day of the first month, Shanggan Nuo activity has a fourstage ritual structure and procedures: having Nuo, 
performing Nuo, relieving Nuo, and setting up a seat. Ganfang Nuo troupe is one of the Nuo troupes with the longest duration in Nanfeng. It is called Shennuo because of the legend that Nuo God is effective. It is said that there was Nuo in Tang Dynasty, and three Nuo temples were built. Now Nuo temple was relocated from Yongle period to Xuande period (1403-1435), located in Shangganfang. The central altar of Nuo Temple worships a wooden statue of Qingyuan Miaodao Zhenjun, with Qianliyan and Shunfenger. In the East, the land was molded, and the tablet of "master of performing exorcism" is erected in the West. During the Spring Festival, dozens of Nuo masks are worshipped at the altar. There is a small attic on the altar to store the holy box and props for Nuo mask. Shanggan Nuo dance is one of the typical Nuo representatives in Nanfeng, which integrates Confucianism, Taoism and Buddhism, and remains ancient Nuo culture factors (see "Fig.3").

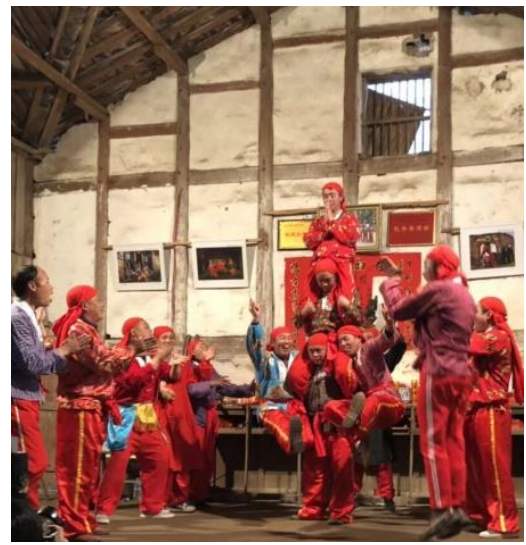

Fig. 3. Shanggan Nuo dance.

\section{Gengxi Zhuma}

Nanfeng Zhuma dance is an important variety of Nuo dance in Nanfeng. However, there are no historical records or legends about when it was handed down. Although it is simple to perform the dance of Guan Gong v.s. Zhou Cang, Hua Guansuo and Bao Sanniang, the story involved is mysterious and embodies its rich cultural heritage.

There are five stages in the structure of Gengxi Zhuma (see "Fig. 4"): starting Zhuma (Qiying), jumping Zhuma (jumping), yuan Zhuma (driving epidemic disease), round bamboo horse (Yuanying) and saying Mass for the departed souls. The performance of Zhuma dance is unique. Taking the duet dance as an example, actors stand on tiptoe when they appear. It seems that they are imitating horse riding, rotating from left to right, leaning forward slightly. They uses one hand to wave dances props, and the other thumbs up. According to local villagers, it means toasting to Xiang $\mathrm{Yu}$. According to the other three fingers, they bend to their palms and hold them under the chin of the mask, just like galloping across a horse. The costume design of Zhuma dance is also very special. Each actor has a wooden horse head on his abdomen and a horseshoeshaped strip tied to his back. The two ends of the strip are connected with the horse's neck. He wears a long skirt and long red and green robes. The front of a garment is opened and the horse's head is extended. The back of the garment is longer than the front, and the lower hem is draped from the strip. The back shape of the horse is naturally formed. A long shawl is tied on the head and the inscription "being in front of Junshan Dadi" is written. In addition, he wears a painted mask, holds a military flag or a magic weapon in his hand, and dresses up as a martial arts man. According to the implication of Gengxi Zhuma, it is time to "put the sword and gun into storage, and let the horse go to the South Mountain". The world is peaceful and people can live and work in peace and contentment.

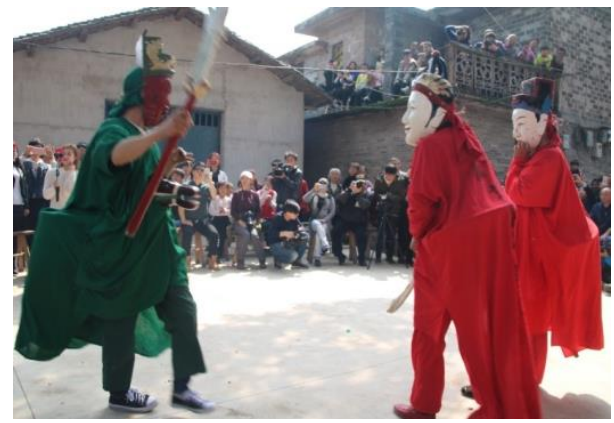

Fig. 4. Gengxi Zhuma.

\section{Shuibei Hehe}

Hehe dance, shown in " "Fig. 5", is a kind of Nuo dance in Nanfeng, and Shuibei Hehe dance is the most famous. The ceremony of "Hehe dance" in Shuibei village is relatively simple, and the procedure can be divided into three stages: qi and he (starting and welcoming), Hehe, and yuan. The two immortals of Shuibei Hehe name $\mathrm{Fu}, \mathrm{Xi}$ and Bao, holding pen, ink and abacus. The two masks are also carved. They both have golden face and black hair, with red curls on their ears, and they are smiling and exuberant. Wen Xiang, with no bun, is called Laifu, also known as Laixi. He takes wooden brush and ink, expressing the desire for fame and being on the gold list as early as possible. $\mathrm{Wu}$ Xiang's hair is in two buns and called Laibao. He takes five abacus, wishing the business smooth and life auspicious.

"Hehe" culture is one of the quintessence of Chinese culture, and is also the common name of "He Xian" (和 仙) and "He Xian" (合仙) in China. Since Ming Dynasty, local farmers have danced in the first month of each year to pray for social harmony, peace, agricultural harvest and abundant crops. A variety of philosophy 
and cultural concepts, such as harmony, harmonious coexistence, a harmonious union lasting a hundred years, harmony and reunion, harmony bringing wealth, and yin and yang, all permeate into the "Hehe dance" of Nanfeng Nuo dance. This is Shuibei Hehe dance, and it also expresses the wish of all Hehe dance in Nanfeng.

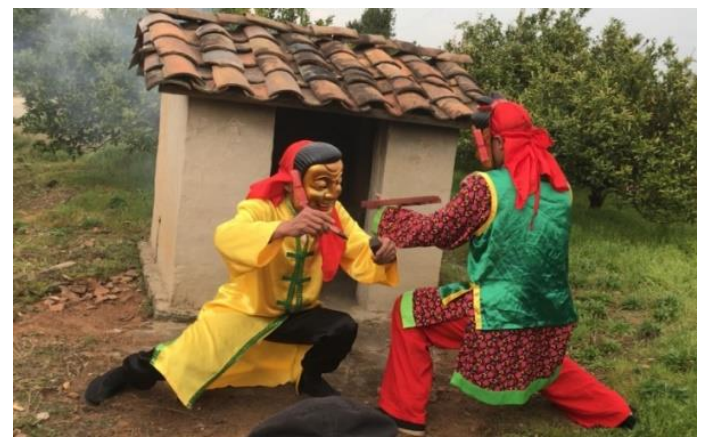

Fig. 5. Hehe dance.

\section{ANALYSIS ON THE FARMING CULTURAL CHARACTERISTICS OF NANFENG NUO DANCE IN JiAngxi PROVINCE}

There are two cultural themes of "exorcism" and "praying for harvest". In the historical development, the cultural theme content of Nuo dance has been expanded. Generally speaking, there are three basic types of Nuo dance, which are mainly on "exorcism", "praying for harvest" and "praying for good luck". Under the influence of farming culture, the purpose of Nanfeng Nuo dance is to entertaini gods and people. The performance contents of these dances are closely related to people's labor production and daily life.

\section{A. Sacrifice custom}

Liu Zhao annotated the "Book of the later Han Dynasty": "Nuo can help Yang and suppresses Yin." However, the purpose of Nuo dance in spring is to "help pray for the beginning of agriculture". It can be seen that the content of rural Nuo dance in Han Dynasty has the content of praying for New Year, reflecting the close relationship between rural Nuo dance and farming culture $^{3}$. The combination of exorcism and praying for good weather and peace has evolved into colorful ritual folk activities.
Liu Yonghong, Zhu Jiang. The farming culture characteristics of Nanfeng Nuo dance in Jiangxi [J]. Agricultural Archaeology, 2012. 01: 141

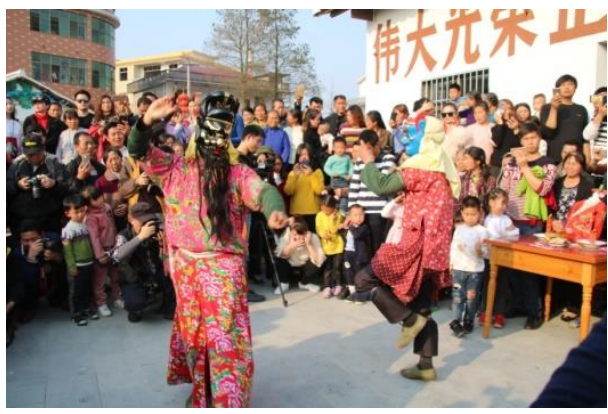

Fig. 6. Shiyou Nuo dance.

From the performance season, the performance of Nanfeng Nuo dance is generally carried out during the Spring Festival. Spring Festival is commonly known as "the new year", and the original meaning of "new year" is related to farming rituals. In the traditional sense, the "year" itself has the meaning of farming rituals. The grain is ripe once a year. "Shuowen" explained: "year represents the ripe grain." 4 It is necessary to worship the God of grain with a year's crops harvest. "Nian" and "Sui" are the same time units in "Erya". In oracle bone inscriptions, "Sui" is like cutting off people's feet with an axe, which is used to sacrifice to the God of valley. It can be seen that the ancient custom of New Year's festival is to sacrifice people to hold sacrifices. The original meaning of "New Year Festival" is to celebrate the bumper year and pray for a bumper harvest in the coming year.

From the performance content, the Nanfeng Nuo dance includes starting Nuo, performing Nuo, searching Nuo and yuan Nuo. The content of each part caters to the Spring Festival cultural theme of good weather a harvest, and fully reflects the relationship between the Nuo program and farming rituals. For example, in the ceremony of "searching the Nuo" in Shiyou village, the disciples cast chopsticks to predict the situation of grains and six Chinese animals in that year. Another example is Gengxi Zhuma. Zhuma is the symbol of dragon horse and Kui dragon. The Dragon God is the God of rain. Zhuma contains the meaning of Shangyang dancing for rain. Zhuma prays for rain to welcome spring, and Nuo drives away nagy, harmonize Yin and Yang, and lion dance wards off evil spirits to greet spring, which are the purposes of entertainment activities in Nanfeng.

In addition, the social organization form of Nuo dance is a clan organization based on blood relationship attached to one of the characteristics of farming culture. Nuo dance is not only a personal hobby, but also a common hobby of villages or regions, so it can be called the spiritual culture of the community of life. It

Wang Jiahua. Time node and coordinate reconstruction of traditional festivals - An investigation based on social time perspective [J]. Cultural Heritage, 2016(01): 23-31. 
has the characteristics of national farming culture. At the same time, the closeness and seasonality of farming culture are also the important factors influencing Nanfeng Nuo dance.

In the first month of every year, Nuo troupes come to every house to dance, praying for happiness (see "Fig. 6 "). In the auspicious first month, people can always see the figure of Nuo troupe in the Nuo temple of the village, praying for the villagers to have a good weather and luck in the coming year. This has become a local ritual.

\section{B. Religious belief}

Nuo is the product of primitive religion. It is also a spiritual sustenance of primitive people based on the actual environment at that time under certain historical conditions. It shows the ideal of the people to pray for disaster avoidance and exorcism. It is also a process of people's continuous adaptation to nature. It is not only a ritual, but also a special religious belief.

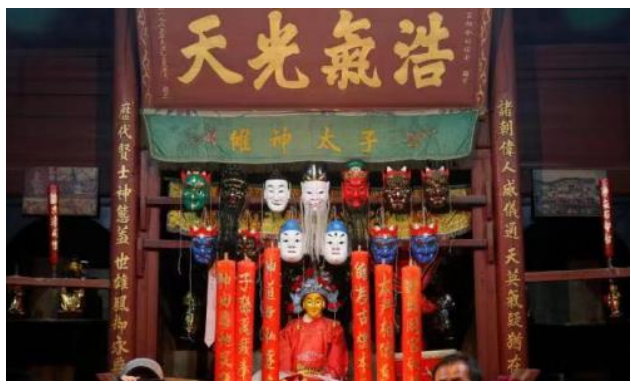

Fig. 7. Nuo mask worshipped in Nuo Temple.

In Nanfeng area, there is a widespread belief in Nuo God, and this belief also has obvious characteristics of farming culture. People think that Nuo God can drive away evil and bring good luck. Every Nuo mask (see "Fig. 7") also represents a kind of Nuo God. Therefore, Nuo worship ceremony is held every year to welcome Nuo God. In many villages in Nanfeng, Nuo temples or other public places of worship are built, such as the Nuo temple in Shiyou village and the Fuzhutang in Chibo village of Baishe Town, where Nuo God is worshipped. In the Nuo Temple of Nanfeng, the Nuo God in the middle of the temple can be different. However, the God of land must be on the left side of the altar, which is commonly known as the father-inlaw of land. The God of land was a belief based on the farming economy in ancient times. It was once famous for a time. The emperor, the princes and the people worshipped it as the God of society. Nanfeng Nuo Temple had the God of land, which reflected the ancient consciousness of the local Nuo to thank the land for its nurturing and pray for a bumper harvest.

In addition, it is worth mentioning that Nuo Gong and Nuo Po are called Tian Gong and Tian $\mathrm{Mu}$ in
Shiyou's "Nuotaizi Mingci". Nuo Gong and Nuo Po were originally the God of Nuo creation and the belief of reproduction worship. They were called Tian Gong and Tian $\mathrm{Mu}$, which combined the reproduction of Nuo sacrifice with the praying for agriculture and high yield of wax sacrifice. This is the natural relationship between the two in the process of agricultural production.

In the long-term life and production practice, the people of Nanfeng have formed their unique multi religious beliefs, such as Taoism, Buddhism, and local gods, among which Confucianism, as a kind of social morality, also plays an important role in people's belief system. These are reflected in the worship ceremony of different Nuo gods. For example, the gods, ghosts, immortals believed in Taoism have corresponding identities in Nuo gods. Nanfeng Nuo also includes the content of praying for rain, curing diseases and prolonging life and other Taoist magics. Therefore, Taoism was popularized with the help of Nuo folk custom. The Nanfeng Nuo also has the worship of Maitreya Buddha. People believe in the causal relationship of "good will being rewarded". They agree with the Buddhist concept of reincarnation of life and death. Nanfeng Nuo dance also teaches people to do good. Nanfeng Nuo dance embodies the essence of Confucian "harmony", and "hehe" dance is a typical representative.

Nuo God belief is not only a special religious belief, maintaining the spiritual dependence of the people, but also a special cultural carrier to eliminate people's psychological fear and express their expectations for a better life through rituals. For the current Nanfeng Nuo dance, Nuo belief is also the basis of its cultural heritage, and this spiritual core is still dependent on the public.

\section{Reproduction worship}

In Tang Lizhuo's "Qin Zhong Sui Shi Ji": "in New Year's Eve, all of them are ghosts and gods, and the two are named Nuo Gong and Nuo Po." ${ }^{5}$ This is the earliest record and the oldest two Nuo gods. Nuo Gong and Nuo Po are the creation gods of Nuo and the embodiment of reproduction worship. In the agricultural society, especially after the patriarchal society, it needs a lot of manpower whether to resist foreign enemies and natural disasters, or to work hard, so the prosperity of the population has become the common appeal of human reproduction and development.

Sun Zhongliang. Inheritance and Innovation of Folk Nuo Dance Sports Culture in Jiangxi under the Protection of Intangible Cultural Heritage [D]. Nanchang University, 2019: 38. 


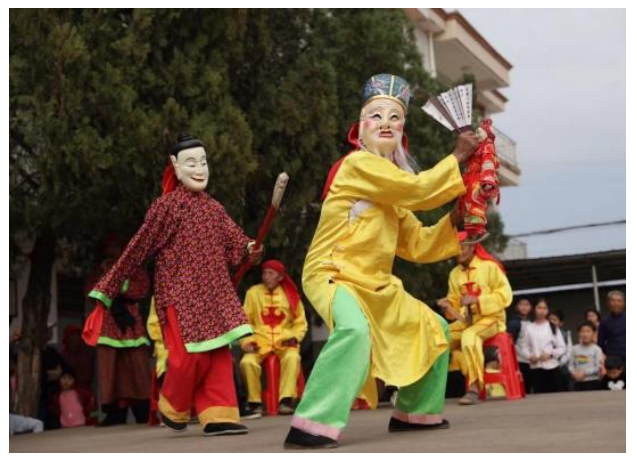

Fig. 8. "Nuo Gong and Nuo Po".

"Nuo Gong and Nuo Po", shown in "Fig. 8", is a necessary program for Nanfeng Nuo Troupe (except for some troupes). Each Nuo troupe has its own characteristics. The Nuo Gong of Shiyou village wears an official hat, his eyebrows are sparse, his eyes are smiling, his white-collar is bright, his mouth is crooked to the right, and he is gentle and elegant. Nuo Po's head is covered with panjiang, her lips are red, her face is white, her eyebrows are curved and her eyes are beautiful, and her mouth is tilted to the left. Nuo Gong is on the stage with his staff and folding fan. Nuo Po holds Nuo son and follows up with handkerchief. Nuo Gong hugs Nuo son for fun, and Nuo Po takes longevity stick to help. Nuo Gong puts a hairpin in Nuo Po's hair, and the couple kisses each other. Nuo Gong and Nuo Po wipes nose, urinate and fan for Nuo son. The husband and wife take care of each other. The dance is warm and lively, full of peace and happiness. However, Nuo Gong in shangganfang is an old man with red rope and white hair, and he does not have the happiness and elegance of Nuo Gong in Shiyou. Nuo Po is a middle-aged woman, and she does not laugh or crook her mouth. She holds Nuo son in her arms and takes a cattail leaf fan, a bamboo basket and a folding chair to sit down. Nuo Po first teaches Nuo Gong to weave, but Nuo Gong is too clumsy. Then Nuo Gong holds Nuo son, but Nuo Gong is unwilling and afraid of his wife. When Nuo Po is tired and sleepy, Nuo Gong wakes Nuo son intentionally, and refuses to let Nuo mother feed her. Nuo Po gets angry and asks Nuo Gong to kneel down. Nuo Gong admits his mistake and the couple make up. The whole dance is humorous and full of strong life atmosphere.

Nuo son is the descendant of Nuo Gong and Nuo Po. They are made of puppets and used as performance props when dancing Nuo. They have different performances in different occasions, implying having children and with the color of primitive sympathetic witchcraft.

"Nuo Gong and Nuo Po" is the object of reproduction worship of Nanfeng villagers. It can be used as a ritual dance performance, an entertainment dance performance and a praying dance performance. For example, after "Jienuo" in Shangganfang dancing "Er Lang Fa Gong" to pray for children, "Nuo Gong and Nuo Po" is performed to show that Nuo Gong and Nuo Po give birth to children. Shanggu village, Zhufang village and other large Nuo troupes dance "Nuo Gong and Nuo Po" to celebrate the marriage and pray for the early birth of a noble son. For example, when villagers dance Nuo, troupe disciples will dance in the room of new daughter-in-law and obtain a reward. In a word, "Nuo Gong and Nuo Po" in Nanfeng is not only the object of reproduction worship, but also the role of eliminating evils and disasters.

\section{CONCLUSION}

Nanfeng Nuo dance has the production and development imprint of farming culture. It is people's good hope for prosperous population, abundant grain and disaster relief. With the development of the society and the changes of the times, Nanfeng Nuo dance has gradually moved from the remote area to the public's vision. From the local people's self-entertainment and piety, it has become the symbol of local culture. As a traditional form of dance in Nanfeng folk activities, Nanfeng Nuo dance is only a drop in the ocean in the Grand View of Chinese culture. Today, rural culture and urban culture blend and coexist, and the changes of material culture and institutional culture have changed the original ecological environment of Nanfeng Nuo dance. Its traditional inheritance mode has gradually constructed a new form with the requirements of the contemporary environment. Especially, with the participation of foreign personnel, it has broken the original pattern of Nanfeng Nuo dance culture in the past. In today's era of cultural consciousness, the function of Nanfeng Nuo dance is constantly expanding. The activities of Nanfeng Nuo dance are no longer limited to worshipping gods and ancestors or people's leisure and self-entertainment. The government, scholars and commercial organizations will gradually infiltrate or participate in it. This has to be said to be the development opportunity of Nanfeng Nuo dance. However, it is necessary to be aware that the original ecological Nuo dance ceremony of people's self-entertainment is in an endangered state. Therefore, how to better protect and inherit the folk dance culture represented by Nanfeng Nuo dance deserves further consideration and research.

\section{References}

[1] Zeng Zhigong. Nanfeng Nuo Culture in Jiangxi [M], China Drama Press, 2005. (in Chinese)

[2] Editorial board. Chinese Dance: Jiangxi Volume [M]. Xuelin Publishing House, 2001. (in Chinese) 
[3] Nanfeng County Annals Compilation Committee. Nanfeng County Annals $[\mathrm{M}]$. Tsinghua Tongfang Electronic CD Press, 2006. 12. (in Chinese)

[4] Shu Siqiang. Research on the Inheritance and Protection of Nanfeng Nuo Dance from the Perspective of Intangible Cultural Heritage [D]. Northwest Minzu University, 2017. 05. (in Chinese)

[5] Li Qingwen. Research on Development Status and Countermeasures of Jiangxi Nuo Dance - Taking Nanfeng Nuo Dance as an Example [D]. Nanchang University, 2017.12. (in Chinese)

[6] Gao Haigui. A Study on the Communication of Nanfeng Nuo Culture in Jiangxi - Taking Shiyou Nuo as an Example [D]. Hebei University, 2013.05. (in Chinese)

[7] Zhang Yanran. Performance characteristics of Shiyou Village's "Tiao Nuo" [D]. Beijing Dance Academy, 2015. (in Chinese)

[8] Wang Longsheng. A Study of Nuo Dance Culture in Ningdu, the south of Jiangxi Province [D]. Yunnan Arts University, 2014. (in Chinese)

[9] Liu Yonghong, Zhu Jiang. The farming culture characteristics of Nanfeng Nuo dance in Jiangxi [J]. Agricultural Archaeology, 2012.01. (in Chinese)

[10] Tao Lipan. Farming Festival, Spring Festival Culture and Inheritance Protection [J]. Art Review, 2013. 03. (in Chinese) 